\title{
Educación, enseñanza y didáctica en la contemporaneidad
}

\section{Necuzzi, Constanza [ver currículum del autor, docente de la Facultad de Diseño y Comunicación]}

Resumen: Las formas de

conservación de los saberes son

diversas y han ido variando a lo largo

del tiempo. Podemos reconocer las

sociedades ágrafas (orales) donde la conservación es a través de relatos orales aprendidos y retenidos de memoria, las sociedades alfabéticas (pre y post Gutenberg) con la primacía del libro y, finalmente, las sociedades audiovisuales (en la actual Era de la Información) donde el texto escrito se complementa con imágenes y sonidos.

Los diversos recorridos de las tecnologías de soporte y distribución del conocimiento y las prácticas asociadas a ellas es sumamente interesante (por ejemplo: la historia de la lectura y de la escritura) pero no será objeto de este trabajo. Aquí nos centraremos en la actividad de transmisión de los saberes que ocurre entre los distintos sujetos, sujetos que en esa relación ocupan lugares diferentes tanto en relación con la posesión inicial o no de los saberes como en las posibilidades de su uso y reuso posterior. A esta actividad genérica de transmisión la llamaremos enseñanza. Y llamaremos didáctica al cuerpo teórico que estudia las prácticas de la enseñanza, buscando describirlas, explicarlas y fundamentarlas, a la vez que enunciar las normas para la mejor resolución de los problemas que se presentan en el transcurso de la actividad misma

Palabras clave: educación - prácticas de la enseñanza - didáctica - conocimiento - comprensión - lenguaje universidad.

$\left(^{*}\right)$ Licenciada en Ciencias de la Educación, Especialista en Didáctica y Magister en Didáctica, Facultad de Filosofía y Letras, UBA. Investigadora UBACYT. Docente UBA y UP.

1. La educación, la enseñanza y la didáctica

\section{Cuadernos del Centro de Estudios de} Diseño y Comunicación № 67

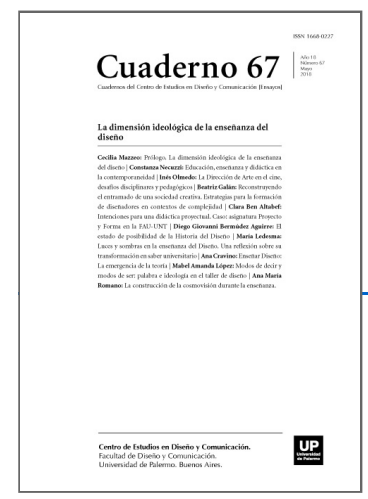

ISSN: 1668-0227

La dimensión

ideológica de la

enseñanza del diseño

Año XVIII, Mayo 2018, Buenos Aires, Argentina | 260 páginas

descargar PDF

ver índice de la publicación

Ver todos los libros de la publicación

compartir en Facebook

Esta obra está bajo una Licencia Creative Commons Atribución-NoComercialCompartirlgual 4.0 Internacional 
En todas las culturas los hombres y las mujeres han desarrollado modos de conservar los saberes (tanto los conocimientos como las prácticas y los significados asociados a su creación, uso y reproducción) y transmitirlos a los niños y jóvenes constituyendo una cierta matriz cultural con sentido en el marco de esas sociedades. Llamaremos educación a la práctica social de proporcionar a los sujetos que conforman una sociedad los medios para estructurar sus propias experiencias en base a los saberes acumulados, de modo que amplíen lo que saben y creen (o duden) y perciban y comprendan el lugar que ocupan en la historia y en el mundo.

Las formas de conservación de los saberes son diversas y han ido variando a lo largo del tiempo. Podemos reconocer las sociedades ágrafas (orales) donde la conservación es a través de relatos orales aprendidos y retenidos de memoria, las sociedades alfabéticas (pre y post Gutenberg) con la primacía del libro y, finalmente, las sociedades audiovisuales (en la actual Era de la Información) donde el texto escrito se complementa con imágenes y sonidos. Los diversos recorridos de las tecnologías de soporte y distribución del conocimiento y las prácticas asociadas a ellas es sumamente interesante (por ejemplo: la historia de la lectura y de la escritura) pero no será objeto de este trabajo.

Aquí nos centraremos en la actividad de transmisión de los saberes que ocurre entre los distintos sujetos, sujetos que en esa relación ocupan lugares diferentes tanto en relación con la posesión inicial o no de los saberes como en las posibilidades de su uso y reuso posterior. A esta actividad genérica de transmisión la llamaremos enseñanza. Y llamaremos didáctica al cuerpo teórico que estudia las prácticas de la enseñanza, buscando describirlas, explicarlas y fundamentarlas, a la vez que enunciar las normas para la mejor resolución de los problemas que se presentan en el transcurso de la actividad misma1.

Ahora bien, al tratarse de relaciones interpersonales, las distintas opciones que adopte esa transmisión denotarán las diversas concepciones que se tenga sobre el alcance social del proyecto educativo. Las finalidades y propósitos de la educación, las perspectivas adoptadas sobre cómo ocurre el aprendizaje, sobre las tareas de la enseñanza, los modos de llevarla adelante, entre los principales, determinarán en buena medida tanto el proceso educativo como sus resultados. El develamiento de esta visión busca reconocer la dimensión ideológica de la enseñanza. ¿Cuáles son los fines de la educación? ¿Estos fines son únicos? ¿Son válidos en todo tiempo y lugar, para todas las culturas? ¿Cómo lograrlos? ¿Cómo convertirlos en prácticas concretas? ¿Qué será enseñado y cómo? ¿Qué insumos y recursos serán necesarios? ¿Qué tiempos demandará? ¿Quiénes están dispuestos a llevar adelante esta tarea? ¿Qué deben saber para poder concretarla? ¿Cómo sabrán que la tarea ha sido exitosa?

2. Una concepción ideológica en el proyecto educativo de la naciente modernidad

Jan Amos Comenio (1592-1670) fue uno de los muchos metodizadores que abundaron en los estados alemanes en el siglo XVII, en un momento de fuertes cambios políticos, sociales y religiosos. En Europa central, y a partir de la acumulación posibilitada por las colonias americanas, se conforma y fortalece una matriz económica, social y cultural que consolidará el capitalismo entre los siglos XVIII y XIX. Lo que hace sobresalir a Comenio entre todos ellos y asumir en la historia de la Pedagogía un lugar fundante, es su pensamiento educativo, donde las opciones que hoy denominamos ideológicas adoptan un claro sentido como parte de sus búsquedas metodológicas para la enseñanza y la educación. Por su carácter de maestro y pastor luterano, confluyen en su obra el misticismo propio de una cosmovisión religiosa, junto al sensualismo de la experiencia apoyado en el naciente empirismo y su concepción de la ciencia basada en hechos y datos. Desde un punto de vista político- 
educativo, Comenio conforma el grupo de reformadores que apoyan la creación de escuelas populares donde se enseña a todos a leer la Biblia en lengua materna, eludiendo la intermediación de la Iglesia entre el hombre y Dios2.

En su obra Didáctica Magna, de 1632, define a la didáctica como "un artificio universal para enseñar todo a todos y totalmente (...) A todos por igual, nobles y plebeyos, ricos y pobres, niños y niñas (...) Es el arte de enseñar y aprender". Es interesante esta idea de artificio, de tecnología, de producto humano con características propias relacionadas con la marca del maestro y también del alumno: se trata de un arte, en clave contemporánea diríamos de un oficio. Y la finalidad es enseñar todo a todos. Es una propuesta inclusiva y $\sin$ distinciones de género en cuanto a los destinatarios. ¿Se trata de la democratización del acceso al conocimiento? El contenido de la actividad está dado por "Las cosas (que) solo tienen importancia dentro del orden, que es cósmico", primando aquí lo religioso. Sin embargo, esa comunión no quita que "todo debe presentarse a cuantos sentidos sea posible. El conocimiento debe empezar siempre por los sentidos. No se debe enseñar nada por la mera autoridad (...) sino que todo debe exponerse mediante la demostración sensual y racional". Encontramos aquí una crítica a la enseñanza con palabras sin las cosas. "Cuando las cosas no sean accesibles, se recurrirá a las imágenes”3. En otra de sus obras, Orbis sensualium pictus, de 1658, selecciona un conjunto de contenidos y los ilustra, buscando ampliar la comprensión a la vez que la utilidad práctica de lo enseñado.

A partir de este enfoque, Comenio postula sus principales postulados en cuanto al método, los cuales son ampliamente conocidos: enseñanza ordenada gradualmente de lo sencillo a lo más complejo, idea de autonomía y suficiencia de cada nivel de instrucción (propone seis niveles de enseñanza básica), eliminación de los castigos físicos en la enseñanza de los contenidos (circunscribiéndolos al área de la conducta), importancia dada a mostrar a los alumnos la utilidad práctica de lo enseñado, propuesta de enseñanza mutua, reconocimiento de la especificidad del espacio de la infancia, entre los principales. Como puede verse, en su perspectiva sobre el método, es decir, el conjunto de las actividades que concretan y hacen posible la enseñanza, no se disocian de la perspectiva filosófica (religiosa, social, cultural y científica) sostenida por el educador.

\section{La enseñanza en clave contemporánea}

A fines del siglo XX, el educador y filósofo de la educación estadounidense Gary Fenstermacher estableció un postulado sobre la enseñanza que logró diferenciarla claramente de su pariente el aprendizaje. A lo largo de las décadas anteriores, enseñanza y aprendizaje se entendieron en la teoría didáctica como un proceso único, articulado por relaciones de causalidad. La analogía elaborada por el autor ha resultado claramente ilustrativa para varias generaciones de educadores: enseñar y aprender están relacionados del mismo modo que correr una carrera y ganarla. Enseñamos para que otro aprenda, como corremos una carrera para ganarla. No existiría la idea de la enseñanza si no hubiera otro que aprendiera, como no existiría la idea de la carrera sino pudiéramos ganarla. Pero, dice el autor, podría ser que corriéramos y no ganáramos, del mismo modo que podemos enseñar y el otro no aprender4 . Por este motivo, afirma, la relación entre un término y otro no es de causalidad, sino de dependencia ontológica. La existencia del segundo depende del primero, no deviene de éste como causa 
Esta conceptualización analítica permitió volver a interpretar los problemas de la enseñanza, especialmente cuando los aprendizajes aparecen como no logrados pues la ausencia de logro no supondría la ausencia de enseñanza. Al analizar las tareas que realizan tanto docentes como estudiantes se perciben grandes diferencias entre ellas. El autor señala: "Los profesores explican, describen, definen, corrigen, estimulan (...) Los estudiantes repiten, practican, piden ayuda, repasan, controlan, buscan materiales de estudio" 5 .

Y desarrolla a continuación una noción que resignifica la vieja idea de la transmisión.

El profesor no transmite el contenido al estudiante (...) más bien instruye al estudiante sobre cómo adquirir el contenido a partir de sí mismo, del texto u otras fuentes. A medida que el estudiante se vuelve capaz de adquirir el contenido, aprende. (...) La tarea de enseñar consiste en permitir la acción de estudiar, consiste en enseñarle cómo aprender (...) permitir al estudiante realizar las tareas del aprendizaje6 .

En esta concepción, las tareas del docente guardan semejanza con la noción de andamiaje que Jerome Bruner construye a partir del concepto de zona de desarrollo próximo de Lev Vigotsky. En sus investigaciones, el psicólogo norteamericano observa cómo, frente a la ejecución de una tarea que un niño no puede realizar solo, la instructora hace lo que el niño no puede hacer, presentando la tarea de manera tal que el chico puede hacer con ella lo que no podía hacer solo. A medida que avanza el proceso de instrucción, el niño asume partes de la tarea, tomando progresivamente el control completo.

La zona de desarrollo próximo -ZDP- es la distancia entre el nivel de desarrollo real determinado por la solución independiente de los problemas y el nivel de desarrollo potencial determinado por la solución de los problemas con la guía de un adulto o en colaboración con pares más capaces7 .

En clave contemporánea la teoría didáctica reconoce los aportes de las teorías cognitivas y sociohistóricas para el análisis de las prácticas de la enseñanza. El docente empieza proporcionando el contenido. El alumno comienza a comprender y a desarrollar las tareas del aprendizaje. Entonces el docente se desplaza de la centralidad del proceso a ser un proveedor de los medios para que los estudiantes puedan estructurar su propia y personal experiencia educativa. Esta instrumentalidad material nos aleja de concepciones idealistas o inmanentistas que suponen que el conocimiento ya está contenido en los estudiantes tanto como aquellas que postulan que el estudiante no posee absolutamente ningún saber y es el docente quién le da todo, depositando el saber en su cabeza y en su cuerpo.

Ahora bien, continua Fenstermacher, no da lo mismo cualquier tipo de enseñanza. Los docentes debemos perseguir la buena enseñanza, definida por su fuerza moral y epistemológica, más bien que por su éxito en términos de logro y cantidad de contenidos aprendidos. "Preguntar qué es buena enseñanza en sentido moral equivale a preguntar qué acciones docentes pueden justificarse basándose en principios morales y son capaces de provocar acciones de principio por parte de los estudiantes". Paralelamente "preguntar qué es buena enseñanza en sentido epistemológico es preguntar si lo que se enseña es racionalmente justificable y, en última instancia, digno de que el estudiante lo conozca, crea o lo entienda"8 . La comprensión que la ciencia está cargada de ideología y de compromiso es parte de la axiología de las comunidades científicas y constituye la posibilidad de cuestionamiento y crítica que valida y reconstruye los postulados educativos. 
Tanto en las concepciones clásicas como en una perspectiva contemporánea, hay un elemento que representa la continuidad que da sentido a la enseñanza: el contenido, el objeto que será transmitido, enseñado y aprendido. ¿Qué debe saber alguien para ser considerado una persona educada? Fenstermacher nos propone un juego.

Supongamos que en una sociedad hay cuatro criterios básicos para reconocer plenamente a una persona educada y darle su tarjeta P.E. -persona educada-: leer y entender material corriente publicado (periódicos, libros, mapas e informes no técnicos); escribir y hablar con argumentos sólidos; hacer los cálculos que requiere la vida cotidiana; estar familiarizado con las leyes y la constitución de la nación en la que el individuo vive.

Podría pensarse que además, conocemos gente que no conoce las leyes o es analfabeta, pero es atenta y servicial, se preocupa por el bienestar de los demás, tiene buen trato. Todo este conjunto constituye posibles contenidos de la educación, con el potencial de constituirse en objetos de la enseñanza. Si se observa este recorrido inicia por lo más básico, en un nivel descriptivo (leer, calcular) y pasa a ser cada vez más prescriptivo (constitución nacional, el bienestar del prójimo). Va desde qué es a qué debería ser. La definición de persona educada se vuelve entonces normativa: especifica normas, es evaluativa, señala características o niveles de logro deseables. Educar es una actividad normativa dirigida a ayudar a los individuos a desarrollarse hacia una imagen de lo que significa ser un ser humano desarrollado y pleno9.

Toda sociedad, afirma el autor, exige de cada miembro una forma de educación que le permita desempeñar un rol productivo en su seno. Cuando una sociedad se compromete a educar a la mayoría de sus niños y jóvenes, suele definir las escuelas como los sitios donde desarrollará esa tarea. En la mayor parte de los países del mundo, las escuelas están financiadas por el gobierno y la asistencia a ellas es obligatoria hasta cierta edad.

Lo que una sociedad define como persona educada también influye y mucho sobre lo que los docentes hacen en sus clases. La visión que se tenga de la enseñanza y la concepción de lo que es una persona educada son dos puntos de vista estrechamente unidos entre sí10.

Junto a Fenstermacher la gran pedagoga argentina Edith Litwin sienta las bases que sostienen una perspectiva contemporánea de nueva agenda para pensar la didáctica. Ella reconoce una agenda clásica en las perspectivas centradas en la planificación de la enseñanza, en el pensar la clase anticipadamente, donde lo central son los objetivos, los contenidos, las teorías del aprendizaje, la evaluación. La reflexión sobre la clase acontecida y el análisis del valor de dicha reflexión al interior de las comunidades de práctica, pivoteando sobre las derivaciones de la psicología cognitiva constituyen una primera superación de este enfoque. Sin embargo, lo que resulta definitorio para un enfoque de nueva agenda es el estudio de la clase en su transcurrir: el papel de lo espontáneo, las intuiciones, la conformación de una sabiduría práctica, lo situado como rasgo propio de las prácticas de enseñanza11.

Litwin se pregunta a qué podríamos llamar buena enseñanza en una perspectiva de nueva agenda. Frente al recetario/decálogo/conjunto de recomendaciones que usualmente conforman la bibliografía sobre el método, la autora e investigadora plantea los alcances y límites de imitar, copiar o reproducir las buenas prácticas de la enseñanza, y si este enfoque no podría configurar un programa que reconoce los modelos y la adopción de buenas estrategias didácticas. 
Así como el arte necesita de la copia de las grandes producciones, por qué no pensar que la enseñanza necesita de la reproducción, reconstrucción y análisis de los modelos de clase que podamos conocer (...) La buena enseñanza no corresponde a una sola manera, sino a muchas (...) Por qué elegimos una estrategia, un modo de explicación, un tipo de respuesta, una metáfora o construimos un caso, siguen siendo interrogantes potentes a la hora de analizar las prácticas de los docentes 12.

Una perspectiva de nueva agenda no niega la importancia de la planificación. Pero muestra sus límites en tanto la enseñanza es similar a otras prácticas que requieren la ejecución de muy diversas actuaciones en tiempo real, en contextos impredecibles y de incertidumbre. El hecho educativo es complejo y requiere liberarse de los reduccionismos con los que se construyó la didáctica13. ¿Por qué razones se sostienen y afianzan ciertas prácticas de la enseñanza? ¿Por qué no desaparecen o se modifican? ¿Sobre qué ideas se apoya la enseñanza, sobre qué bases? La autora afirma que los grandes maestros podrían ser las inspiraciones para el desarrollo de una propuesta autónoma, personal.

Una noción va adquiriendo relevancia en esta propuesta, encontrando un hilo conductor en los planteos de Comenio, pero también de John Dewey, educador y político norteamericano de la primera mitad del siglo XX: el lugar de la experiencia dentro del hecho educativo. ¿Cómo enriquecer, desde las propuestas pedagógicas las mentes de los estudiantes, creando un currículum más significativo para la vida de los jóvenes en esta sociedad? Aquí es central recuperar el conocimiento de las disciplinas, de sus estructuras de significado y de sus aportes al conocimiento del mundo, pero de modo tal, dice Litwin, que los estudiantes sean capaces de abandonar las razones de los otros (incluidas las nuestras en tanto sus docentes) para buscar nuevas o buenas razones propias 14 .

La búsqueda de buenas, nuevas y propias razones, como finalidad de la enseñanza, encuentra fundamento en el reconocimiento de que los temas aprendidos aisladamente, sin conexión con el resto de la experiencia ya adquirida, caen en el olvido. Dewey afirma que cada experiencia es "una fuerza en movimiento, debería provocar curiosidad, fortalecer la iniciativa, crear deseos y propósitos intensos, preparar a la persona para ulteriores experiencias de una calidad más profunda y expansiva"15

Las experiencias solo pueden valorarse en contexto. Una experiencia tiene lugar cuando ocurre una transacción entre un individuo y lo que en ese momento constituye su ambiente. Interacción y situación son inseparables. Dewey formula el principio de continuidad de la experiencia: situaciones diferentes se suceden unas a otras. Siempre se lleva algo de la anterior a la siguiente. Esto puede ampliar o contraer el mundo del sujeto. Lo que se ha adquirido en conocimiento y habilidad en una situación se convierte en instrumento para comprender o tratar efectivamente la situación siguiente. El proceso sigue en tanto la vida y el aprendizaje continúan. La continuidad da la medida de la significación y valor de la experiencia misma.

Litwin postula que para ser educativa, la experiencia debe conducir a un mundo expansivo de materias de estudio, constituidas por hechos, informaciones e ideas. El educador considera a la enseñanza y el aprendizaje como partes de un proceso continuo de reconstrucción de la experiencia. Puede hacer esto cuando dirige su mirada hacia adelante y contempla toda la experiencia presente como una fuerza activa que influye lo que serán las experiencias futuras 16 .

4. Los profesores y la enseñanza 
Philip Jackson reconstruye dos perspectivas para el análisis y la reflexión sobre las prácticas de enseñanza y el lugar de los profesores en ellas. Las llama tradiciones. Las tradiciones se encuentran presentes en diversos casos históricos conocidos y sus diferencias no son evolutivas (una supera a la otra) ni sus límites son temporales (no se suceden cronológicamente). A los fines de reconocer ambos enfoques las denomina tradición mimética y tradición transformadora.

En la tradición mimética, la transmisión del conocimiento se realiza de un modo esencialmente imitativo. El conocimiento a transmitir es, por definición, identificable antes de ser transmitido. Es un

Conocimiento de segunda mano, no en el sentido peyorativo de la expresión, sino por haber pertenecido a alguien antes de poder ponerse en manos de otros (...) es un conocimiento presentado al alumno, y no descubierto por él (...) Además es separable de las personas mismas, puede preservarse en libros, películas, de modo que sobrevive a quienes lo poseyeron. (En tercer lugar) puede reproducirse (...) se asemeja a un mensaje verbal. (Finalmente) puede juzgárselo verdadero o falso, exacto o inexacto, correcto o incorrecto, a partir de una comparación con el conocimiento del docente o con algún otro modelo que figure en un texto o en otros materiales didácticos 17.

¿Cómo se alcanza la meta de la educación en esta tradición? A través de cinco pasos: sometiendo a prueba al estudiante para analizar si ya conoce el material o sabe ejecutar la destreza en cuestión; presentando el material nuevo; ejecutando el alumno la práctica o demostrando que posee el conocimiento y evaluándolo el docente para juzgar el desempeño; premiando al estudiante en caso de desempeño correcto de modo de fijarlo o iniciando un circuito correctivo en caso de desempeño incorrecto; avanzando hacia el material siguiente18.

De modo alterno, la tradición transformadora se propone lograr un cambio formativo en el estudiante, incluyendo entre los contenidos a transmitir los rasgos de carácter y personalidad valorados en una sociedad. Si en la tradición mimética la imagen es la suma, la acumulación, en la transformadora la imagen remite al alfarero que trabaja la arcilla de manera artesanal, moldeándola de modo creativo para obtener un producto artístico, único. Esta tradición reconoce tres rasgos del docente y sus prácticas: su ejemplo personal, el uso de la persuasión blanda y el empleo de narraciones. Los docentes deben personificar las cualidades que procuran inculcar a sus estudiantes, pues "no puede enseñarse ninguna actitud, interés o valor si el docente mismo no cree, quiere o valora aquello que muestra para ser emulado"19. En paralelo, muestra su autoridad pedagógica de modo más moderado, interrogativo y humilde. Finalmente, los distintos tipos de historias ocupan un lugar (mitos, cuentos, parábolas, relatos) que, aunque no visibilizan de inmediato sus propósitos, construyen para los estudiantes intereses y rasgos de carácter, virtudes y valores, señalando cómo pensar, analizar y debatir, proponer y compartir y, en definitiva, cómo vivir. Es interesante cómo el ejemplo personal del profesor es señalado reiteradamente por diversos autores como parte constitutiva de la enseñanza. Fenstermacher señala que para dedicarse a la educación el docente debe poseer un estilo que incluya virtudes morales e intelectuales. Entre las primeras destaca la honestidad, el respeto, la amplitud de criterio y la fiabilidad. Entre las virtudes intelectuales sobresalen la humildad, la creatividad, la aptitud reflexiva y la imparcialidad (en el momento y lugar adecuados). "El estilo de una persona que posee estos rasgos de carácter se aprende copiando, frecuentemente a personas que son así, y viéndose animado a imitar a estas personas y a adaptar las propias acciones a las exigencias de estas características"20. 
Los rasgos que los docentes debieran tener para desarrollar las tareas de enseñanza llevó al profesor estadounidense Ken Bain a preguntarse por aquello que hacen, por cómo son las prácticas de enseñanza que desarrollan los profesores considerados buenos docentes en sus instituciones por los estudiantes. ¿Qué hacen los mejores profesores? La respuesta que encuentra es significativa: lo importante no es qué hacen, sino qué comprenden y cómo piensan sobre lo que hacen.

A la par de la planificación de las clases y las notas para las lecciones magistrales, los buenos docentes comprenden de cierta manera particular su disciplina y valoran de cierta manera particular el aprendizaje de los estudiantes (...) Conocen sus materias a fondo (...) Saben cómo atraer y desafiar a los estudiantes, provocando en ellos respuestas apasionadas (...) Creen que la enseñanza es importante y que los estudiantes pueden aprender21.

La investigación de Bain abarcó 24 universidades norteamericanas, 70 profesores y se desarrolló a lo largo de 15 años de investigación22. En los cientos de entrevistas que realizó a estudiantes pueden reconocerse las marcas de la tradición transformadora caracterizada por Jackson. Entre los principales señalamientos los estudiantes hablaron de cuánto llegaron a entender y como resultado a recordar en el contacto con esos profesores; reconocieron, en el devenir del curso, lo mucho que no sabían, aprendieron a pensar de manera diferente, reflexionaron que el contacto intelectual y afectivo con ese docente cambió sus vidas modificando incluso aquello que habían previsto hacer23.

Los hallazgos dan cuenta de la validez de los planteos de la nueva agenda, que señalan los límites de centrar la atención de la didáctica en la planificación y proponen entender las actividades de enseñanza como prácticas situadas, con rasgos particulares según los sujetos que las protagonizan.

\section{La enseñanza es una práctica situada}

Planificaciones, casos exitosos, tradiciones, rasgos y caracteres de los docentes, de las prácticas que desarrollan, de los contenidos que enseñan, de los propósitos que toda la empresa educativa supone...

Podemos seguir enumerando y sin embargo, hay un componente central que es la historicidad del hecho educativo, su naturaleza única, su irrepetibilidad como acontecimiento personal y social y la perspectiva de inteligibilidad que adoptemos, el posicionamiento ideológico en torno al acontecimiento y su comprensión. Estrategias, actividades y rutinas componen una clase original para cada docente y cada grupo de estudiantes en un cierto momento y en un cierto contexto histórico. Y la comprensión de todos estos elementos dependerá del enfoque o perspectiva que decida cada vez asumirse. De aquí que consideremos a la enseñanza como una práctica situada.

Litwin considera que los objetivos de la propuesta pedagógica consisten en ofrecer herramientas pedagógicas y culturales que amplíen la visión y el tratamiento de los temas, abran interrogantes, rompan con los tratamientos ritualizados y promuevan una mirada amplia e inquisitiva de las experiencias docentes.

Recuperamos tres grandes ejes de su propuesta pedagógica: las preguntas, las ayudas y la pasión por el conocimiento24. Sobre las preguntas, Litwin señala que introducen lo nuevo por venir, conectando lo que ya se sabe y dotando de sentido al contenido. Establecen la continuidad entre temas y problemas. Ayudan a la 
cognición de los estudiantes mostrando la información desplegada. Finalmente cumplen una función central para el avance en la construcción del conocimiento: permiten comparar los procesos de pensamiento de profesores y alumnos, en ese complejo y dinámico proceso de andamiaje que describimos anteriormente. Las preguntas metacognitivas habilitan el reconocimiento de cómo se están pensando los temas, si las síntesis y generalizaciones son adecuadas, si es apropiado desarrollar un pensamiento analítico o el contenido requiere un pensamiento abductivo y simulador. Las preguntas epistémicas reconocen la provisionalidad del conocimiento, cómo se lo obtuvo y validó, los debates en torno a él.

Por otro lado, las preguntas en la clase permiten y favorecen la participación de los estudiantes, les devuelven la palabra, hacen explícitos sus procesos de pensamiento, transparentándolos para el docente y para los compañeros.

Fuertemente Litwin señala aquellas preguntas que no deberían hacerse: las capciosas, las que se responden por azar, las binarias, las demasiado amplias. Las preguntas de la clase deben ser capaces de generar un ámbito de reciprocidad, establecer un diálogo como actividad dirigida al descubrimiento y a una comprensión nueva. Para ello es significativo reconocer el nivel de pensamiento que intentan estimular: si se trata de preguntas sencillas, preguntas de comprensión, preguntas de orden cognitivo superior, preguntas metacognitivas.

Neil Mercer, educador e investigador británico, reconoce a partir de sus investigaciones en el aula el modo en que las preguntas promueven el pensamiento del conjunto de la clase. Allí resulta clave la capacidad de espera del docente, el guardar silencio por un período breve de tiempo que habilita el pensamiento. Permanecer en silencio sólo algunos segundos, evitando llenar rápidamente el silencio posibilita a los estudiantes que necesitan más tiempo la expresión de sus ideas, dudas y hallazgos. Aprender a escuchar y parafrasear a los estudiantes se convierte en una habilidad importante a la hora de conducir un aula pensante25. A través de las preguntas de la clase el docente enseña a los alumnos a profundizar en niveles cada vez mayores de comprensión, demostrándoles cómo organizar la información, estimulándolos para que formulen sus propias preguntas, enseñándoles que existen distintos tipos de interrogantes.

Sobre las ayudas que podemos ofrecer a los estudiantes nos preguntamos ¿cómo favorecer sus comprensiones? Nuevamente Litwin señala que nombrar, titular e instalar el tema de la clase sigue teniendo vigencia en la construcción de un aula comprensiva. Dar cuenta del contexto en que surge el tema ubica y sitúa, explicando las razones. Las explicaciones basadas en conocimientos relacionales también las mejoran y las favorecen.

Al presentar el contenido a los estudiantes debe considerarse la jerarquía y la secuencia: qué es central, qué es accesorio, cómo ordenar las ideas. Construir analogías y metáforas es central en tanto no se trata de comparar de cualquier modo, sino dando sentido y generando procesos reflexivos. Elaborar generalizaciones, síntesis, abstracciones, conclusiones, resolver problemas, dar ejemplos. Generar preguntas a partir de los hechos, formular hipótesis que los expliquen, recolectar datos, evaluar esas hipótesis. El pensamiento complejo del docente generando y transparentando todos estos procesos para los estudiantes desarrolla sus comprensiones. El trabajo intelectual en torno a lo que Lev Vigotsky denominó procesos psicológicos de orden superior es central para una formación científica y profesional26. Empero, no significa renunciar a los sentimientos, las inspiraciones, los valores o las pasiones. 
De allí que la pasión por el conocimiento recupere su centralidad en tanto se trata de visibilizar la dimensión humana del hecho educativo y recuperar la complejidad de los fenómenos humanos mismos. La escuela es el lugar nodal para la construcción de la ciudadanía. En este sentido, el tratamiento de los temas desde múltiples perspectivas de análisis hace a la calidad del pensamiento, permite reconocer diferencias, opiniones basadas en justificaciones diversas, razones alternativas. Sostener una perspectiva y apreciarla permite recuperar el punto de vista del otro en tanto reconozco el propio como personal y no como universal, favoreciendo la convivencia en el aula y en la vida.

El pensamiento apasionado quiere llegar adonde aún no se llegó con la imaginación: permite aventurar relaciones y proyectarlas de manera original. Este enfoque genera compromiso con la vida de los estudiantes. Es lo contrario de la racionalidad técnica. Su objetivo es volver desconocido lo conocido. Esto permite reaprender lo conocido, desnaturalizándolo.

6. Las intenciones formativas. El conocimiento en la educación universitaria

Cuando se considera el objeto de la enseñanza, surgen las preguntas acerca de por qué enseñamos y para qué lo hacemos. La definición del contenido a ser enseñado y de las intenciones formativas que posee una sociedad y sus instituciones educativas es clave a la hora de elegir, determinar y circunscribir el conocimiento y los saberes que se consideran valiosos y deben ser aprendidos por los estudiantes.

Se trata de definir qué bienes culturales se pondrán a disposición de los alumnos y de reconocer que dichos bienes poseen un valor económico y social. ¿Quién/es decide/n qué conocimiento es valioso, qué aprendizaje/s es/son importantes, necesarios? ¿Cuáles serán los usos que se le darán al conocimiento?

Las definiciones de política educativa inciden fuertemente en los actos de enseñanza que se dan en el aula. A pesar de ello, ésta mantiene un espacio de relativa autonomía, en la medida en que se trata de una práctica situada (tal como se desarrolló anteriormente). Nos preguntamos: ¿cuál es el currículum que queremos para nuestros estudiantes? ¿Qué y cómo queremos enseñarles? ¿Qué formación deseamos que alcancen? ¿Cuáles son nuestras expectativas a futuro? ¿Y en el mediano plazo?

Estos interrogantes asumen rasgos propios cuando se formulan en el contexto universitario y suponen, siempre, una concepción ideológica sobre la enseñanza. ¿Cuál es la relación de la universidad con el conocimiento? ¿Qué papel juega la universidad en la construcción de esta etapa de la vida social? ¿Qué papel debería jugar?

El conocimiento tiene valor económico para la universidad y para los profesores. Esto produce un deslizamiento hacia la comercialización del conocimiento vinculando las empresas con el Estado y las universidades. A la producción de conocimiento en las universidades y sus institutos de investigación se le suma el sesgo por el uso del conocimiento para la prestación de servicios.

Las intencionalidades educativas se manifiestan en las distintas propuestas que vehiculizan la formación general, la básica, la profesional, la ética y la formación para la ciudadanía27. Las propuestas formativas son construcciones sociales, diseños educativos puestos al servicio de las intencionalidades definidas, tanto explícitas como supuestas. 
Cuando nos referimos a la formación general incluimos el conocimiento que necesitan todas las personas en este momento de la vida social. Ella busca el desarrollo de la razón, de la mente, del pensamiento crítico, de los procesos psicológicos de orden superior. Su meta es el desarrollo personal.

La formación básica es la relativa a algo, es fundante. Se suele llamar básica en relación con la formación profesional. Tiene una base epistemológica y pedagógica. Es sólida y rigurosa, pues da sentido y sirve de apoyo a lo siguiente, a aquello que continuará. Se presenta completa, sin faltas u omisiones a la vez que dinámica y flexible para poder cambiar cuando lo posterior cambie. Sin embargo debe permanecer perdurable en el tiempo, ser evocable, pregnante. Se trata de un sostén que cambia pues es parte de una estructura, no tiene validación por sí misma. Está por tanto, bajo cierto control. Puede reconocerse esta formación por sus niveles: básico, intermedio, avanzado o por sus contenidos: elemental, puro, indispensable.

En tercer lugar, la formación profesional remite a la preparación para el trabajo o para la investigación en un campo del saber. Involucra por tanto una ética, un modo particular, canónico y aceptado, normado, de funcionamiento. También cambia con el tiempo según su capacidad de resolver problemas nuevos o dar mejores respuestas a problemas viejos. Formación general y formación básica se superponen y atraviesan, pues no es posible pensar sin contenidos. A su vez, la definición de los contenidos, las actitudes personales y las habilidades de pensamiento que requiere la formación profesional determinará en gran medida los contenidos, las actitudes personales y las habilidades de pensamiento que se incluirán en la formación general y en la básica, pues forman parte de una misma estructura.

La formación para la ciudadanía atraviesa todos los niveles del sistema educativo (primario, secundario, superior) y se vuelve urgente en el nivel universitario, en tanto los egresados asumirán tareas que suponen actuar e incidir tanto sobre la propia vida como sobre la vida de los otros con quienes convivimos en sociedad. E ejercicio de una ciudadanía plena supone hoy de manera inexorable el acceso a la alfabetización propia del siglo $\mathrm{XXI}$, que integra las nuevas tecnologías como parte de las competencias básicas y generales de la formación y permite, de este modo, la apropiación de los bienes culturales disponibles en el entorno social y cultural28.

La selección de conocimientos y saberes a ser enseñados se organizan y agrupan en asignaturas. Ellas poseen una estructura conceptual y otra sintáctica. Las estructuras cambian con el tiempo, son incompletas y efímeras. Algunas disciplinas presentan una estructuración y codificación fuerte (como las ciencias naturales) y otras, en cambio, manifiestan una estructuración y codificación débil (como las ciencias sociales)29. ¿Cuáles son los desafíos que deben enfrentar los estudiantes? ¿Qué deben poder hacer frente a las asignaturas? Existen acuerdos en torno de la necesidad de que los estudiantes conozcan la existencia de las distintas clases de conocimiento, reconozcan el modo en que las distintas habilidades permiten utilizar ese conocimiento, entiendan el significado y la naturaleza de lo que están aprendiendo (si es generalizable o no), identifiquen cuándo es necesario aprender más y cuándo es necesario pedir ayuda. Y finalmente reconozcan cuándo el conocimiento se sale de los límites de lo conocido (en un interesante proceso reflexivo llamado metacognición) y requiere de habilidades distintas, caminos nuevos, saltos de pensamiento.

\section{El conocimiento y la comprensión. La centralidad del lenguaje}

Reparar en el qué de la enseñanza nos lleva a reflexionar sobre los problemas que su aprehensión nos plantean a las personas y, por tanto, a los docentes y a los estudiantes. Conocer y comprender son procesos diferentes, 
donde el primero remite a un estado de posesión y el segundo a un estado de capacitación30. Como afirmó Jerome Bruner, la comprensión es "ir más allá de la información dada" 31 , teniendo en cuenta que los datos y los conceptos forman mosaicos con espíritu, estilo y orden propios.

El conocimiento es algo que se encuentra en la mente de cada sujeto, que existe en su pensamiento. Es también una posesión conjunta porque puede compartirse de forma muy efectiva con otras personas. De entre todos los seres vivos los humanos estamos especialmente preparados para utilizar nuestros recursos mentales y solucionar problemas a través de un esfuerzo mental conjunto. Tanto así, que la historia del desarrollo humano muestra que el descubrimiento, el aprendizaje y la resolución creativa de problemas son raramente, o casi nunca, verdaderas actividades individuales. Todos los pensadores creativos, incluso los más famosos, han trabajado con otras personas y con las ideas de los otros además de las propias. Algunas de las individualidades más famosas en sus campos de conocimiento han sido la parte visible de un esfuerzo colectivo que aumentó la calidad de cada contribución individual. El resultado es el vasto y dinámico recurso de conocimiento que llamamos cultura.

Las sucesivas generaciones se benefician de la experiencia del pasado a través de sus productos. De entre ellos sobresale especialmente el lenguaje. Ya sea hablado o escrito, cada nueva generación utiliza el lenguaje para compartir, discutir y definir sus nuevas experiencias. El lenguaje es mucho más que un medio para formular ideas y comunicarlas: es un medio para que las personas piensen y aprendan conjuntamente. La alfabetización, la ciencia y la tecnología son productos del lenguaje. La particularidad del lenguaje es que su función cultural (comunicar) y su función psicológica (pensar) no están realmente separadas32.

El lenguaje habilita el aprendizaje de los estudiantes a través de la conversación y el diálogo en el contexto del aula. Esta conversación puede darse con el docente o entre los estudiantes. La conversación generada por la actividad fuerza a los estudiantes a revisar y extender su marco conceptual. La mejora de la comprensión es una realización conjunta, social y comunicativa.

En el contexto del aula, las relaciones de poder implicadas en la construcción del conocimiento pueden ser bastante complejas. No se puede progresar sin la aceptación parcial, tanto por parte del profesor, como por parte de los alumnos, de la legitimidad y el valor de las actividades que están realizándose. Si los alumnos no entienden el propósito de las tareas que el docente les pide que hagan es improbable que mantengan el entusiasmo. En demasiadas ocasiones las escuelas no dan razón de las tareas que proponen a los estudiantes ni sus propósitos, y no explicitan los criterios con los cuales evalúan luego su realización. Por otro lado, existen formas importantes de aprendizaje que tienen más posibilidades de ocurrir cuando los alumnos pueden hablar y trabajar juntos sin el docente. El aprendizaje también ocurre en la conversación con los pares, y el diálogo permite compartir las intuiciones y dudas con los compañeros.

Los estudiantes necesitan implicarse en nuevos aprendizajes para consolidar la propia comprensión. Esto no se puede hacer simplemente escuchando información presentada clara y lógicamente por un experto. Si lo que se pretende es que comprendan y retengan el conocimiento necesitan utilizar información ellos mismos y aplicarla bajo distintas condiciones. Las actividades de comprensión suponen explicar, ejemplificar, aplicar, justificar, comparar y contrastar, contextualizar, generalizar. La comprensión no es algo que se da o no se da. Es un proceso abierto y gradual. David Perkins plantea que la gran meta de la pedagogía de la comprensión es 
capacitar a los estudiantes para que realicen una variedad de actividades de comprensión vinculadas al contenido que están aprendiendo, pues el aprendizaje es consecuencia del pensamiento33.

En este proceso ocupan un lugar central las imágenes mentales, un tipo de conocimiento holístico y coherente, representaciones unificadoras y abarcadoras que ayudan a elaborar un tema. Las imágenes mentales son el lado interno de la comprensión.

Así pues, el diseño de propuestas de enseñanza supone concepciones sobre el conocimiento, los estudiantes, el aprendizaje y la enseñanza.

En cuanto al conocimiento nos preguntamos: ¿qué significa conocer? ¿Cómo se construye conocimiento en cada una de las disciplinas que se enseñan? Quién enseña pone en acción la idea que tiene acerca de cómo se construyó el conocimiento de su propia disciplina y una perspectiva acerca de cómo aprenden los alumnos, cómo construyen el conocimiento en general y cómo lo hacen en particular en su campo de conocimiento.

Los docentes también poseen concepciones sobre los estudiantes. ¿Cuáles son las características de los estudiantes que recibimos? ¿Están capacitados para aprender? ¿Todos están igualmente capacitados para aprender, o sólo lo están algunos de ellos? ¿Mi función como docente universitario es identificar aquellos estudiantes que son capaces de aprender, seleccionarlos y promoverlos, dejarlos avanzar? ¿O sería alguna otra?

En relación con el aprendizaje, nuestras ideas acerca de él y de cómo son quienes aprenden son centrales a la hora de abordar el currículum pues inciden en el tipo de graduado que queremos formar, la imagen mental que tenemos del futuro graduado. Nos preguntamos entonces, ¿cómo se forma un graduado? ¿Y un profesional? ¿Y un investigador?

Finalmente, y en relación a las concepciones sobre la enseñanza, nos interrogamos sobre si creemos que al enseñar de determinada manera los alumnos van a aprender y van a hacerlo tal cual pretendíamos que ellos aprendan. ¿Cuáles son las estrategias de enseñanza que tenemos que utilizar para que los alumnos realicen determinados aprendizajes? Nuevamente, ¿cómo se forma un graduado? ¿Y un profesional? ¿Y un investigador?

8. La docencia es un oficio en el nuevo siglo

La docencia es un conjunto de prácticas a través de las cuales los profesores llevan adelante la enseñanza. Se trata del ejercicio de un oficio, de una labor con conocimientos estipulados, que acopia experiencia y realiza un armado artesanal de esa práctica, reflexionando sobre ella y, al hacerlo, puede cambiarla y modificarla34.

Estas prácticas diferencian estrategias, actividades y rutinas. ¿En qué consiste cada una de ellas? Las estrategias de enseñanza son el conjunto de decisiones que toma el docente con el fin de promover los aprendizajes de los estudiantes. Se trata de orientaciones generales que inciden en cómo se enseñan los contenidos. Se expresan en tres momentos: la planificación, donde se anticipa la acción; la acción, el momento de la clase propiamente dicho; y la evaluación de la implementación, donde se reflexiona sobre los resultados obtenidos. Las actividades, en tanto, son la concreción de las estrategias decididas. Se trata de instrumentos para crear situaciones y abordar contenidos que permiten a los alumnos vivir las experiencias necesarias para 
su propia transformación. Proponen tareas que los estudiantes desarrollan para apropiarse del conocimiento. Lo central en el diseño de la propuesta es tomar en cuenta los estilos de aprendizaje, los ritmos, intereses, tipos de inteligencia, el tipo de demanda cognitiva que se pretende de los alumnos y el grado de libertad que se les dará para tomar decisiones sobre su propio proceso de aprendizaje.

El sentido de las actividades se construye considerando los valores y las representaciones de la cultura y produce determinados intercambios e interacciones. John Dewey y Ovide Decroly, hablaban, a principios del siglo XX, de los centros de interés de los niños. Sostenían que si los contenidos educativos tenían relación con los intereses naturales de los niños, habría un éxito mayor en los aprendizajes.

En la contemporaneidad, llamamos a esta dimensión interés y motivación, correlacionándolas con el entretenimiento y el aburrimiento. Ahora bien, si el sentido se construye ¿no habrá intereses que pueden aprenderse, descubrirse, construirse? Sería restringido dejar librado sólo al interés "natural" de los estudiantes el sentido y direccionalidad de los aprendizajes. Aquí es donde el interés de los niños, jóvenes y adultos en situación de aprendizaje debe poder cruzarse con las intenciones formativas de una sociedad y las determinaciones curriculares a las que se arribe.

Finalmente nos preguntamos qué son las rutinas. Se trata de acciones repetidas que implican un cierto grado de mecanización constituyéndose en estructurantes de la experiencia. La paradoja de las rutinas es que a veces atentan contra la creatividad (cuando sostienen el conocimiento ritual, inerte) pero otras son absolutamente necesarias (cuando construyen hábitos de trabajo o favorecen el abordaje sistemático de un problema) en tanto dan cuenta de procesos económicos del funcionamiento mental. La dualidad de las rutinas nos muestra el desafío de pasar de las rutinas de los docentes a las rutinas propias de cada estudiante que favorezcan sus procesos de conocimiento y comprensión.

Ken Bain se pregunta qué esperan los buenos docentes de sus estudiantes. Y su respuesta es terminante: esperan más. No se trata de que hagan más, lean más, memoricen más, porque eso no necesariamente redunda en más aprendizaje. Se trata en cambio de una compleja red de creencias, concepciones, actitudes y prácticas docentes que buscan y aprecian el valor individual de cada estudiante y, en general, cualquier capacidad que ellos puedan demostrar. El autor afirma que estos docentes tienen fe en que los estudiantes podrán conseguir lo que se proponen. Por tanto establecen estándares altos y creen que los estudiantes podrán alcanzarlos. “...el principal objetivo del curso es el desarrollo de personas creativas, proporcionándoles confianza en ellas mismas. No vamos a intentar meterlas en ninguna clase de molde. Al revés, estamos intentando ayudarlos a que salgan"35.

Los buenos profesores creen que las personas construyen sus modelos mentales, no que simplemente almacenan o absorben conocimientos. Al creer esto, se preguntan cómo lograr esa construcción. Y cómo puede mejorarse. Hacen uso del pensamiento crítico, como herramienta personal y para el desarrollo del pensamiento de los estudiantes. Ofrecen muchas oportunidades de práctica, de modo que los estudiantes repetidamente puedan poner en juego sus habilidades. ¿Cómo dirigen la clase los buenos docentes? Bain plantea los siguientes principios y técnicas: crean un entorno para el aprendizaje crítico natural, consiguen la atención de los estudiantes y no perderla, comienzan con los estudiantes y no con la disciplina, buscan compromisos, ayudan a los estudiantes a aprender fuera de la clase, atraen a los estudiantes al razonamiento disciplinar, crean experiencias de aprendizaje diversas. 
Edith Litwin se pregunta cómo es la construcción metodológica de algunas de las más interesantes propuestas educativas actuales. En momentos donde las generaciones de jóvenes reciben nombres en relación con su interacción con las tecnologías36 (milennials, generación App) las perspectivas que aportan los actuales desarrollos de la didáctica recuperan el sentido educativo de las prácticas como eje para el diseño de las propuestas de enseñanza. Recuperar la epistemología del conocimiento para pensar la propuesta es prioritario, para evitar actividades forzadas que conduzcan a una didáctica disparatada37. La alternativa es enriquecer los temas curriculares con visitas y salidas, consultas a expertos, bibliotecas, enciclopedias y bases de datos, la utilización del método biográfico y los estudios de caso para comprender las decisiones científicas y sociales que contextualizan el conocimiento. Generar integraciones conceptuales genuinas, relacionando conceptos valiosos que entretejan datos e interpretaciones, incorporando los relatos que superen la mera presentación deductiva de los contenidos. Promover diálogos al interior de la clase donde participen todos los actores. Desarrollar una enseñanza tanto en la clase presencial o a través de entornos virtuales donde las tareas pueden tener más tiempo de reflexión o la velocidad de la inmediatez de las redes sociales.

Si ayer la didáctica era un arte en Comenio y hoy es un oficio en Litwin, la continuidad entre cinco siglos está marcada por la impronta personal del docente que al plantearse finalidades en torno al sujeto a formar y el contenido a enseñar selecciona las mejores estrategias y diseña las mejores propuestas para alcanzar los objetivos educativos.

Las tareas de construcción de sentido constituyen el corazón de una didáctica resignificada, que incorpora los intereses de los estudiantes pero también los de los docentes en la propuesta, que utiliza las tecnologías por la pertinencia y potencia para desarrollar el contenido y no por el enamoramiento que generan. Es esta didáctica, profundamente humana, actualizada en las preocupaciones del siglo XXI (siglo tecnológico, en guerra, con conciencia ecológica y diversidad cultural, étnica y sexual, donde conviven el moderno capitalismo financiero y bolsones de esclavitud, tensionado y convulsionado) la que hoy nos compele a dar la mejor clase que podamos dar, la socialmente más comprometida, epistemológicamente rigurosa y cognitivamente arriesgada que podamos imaginar.

Notas

1. Camilloni, A. y otras (2016) El saber didáctico. Buenos Aires: Paidós.

2. Comenio, J. A. (1986) Introducción, por Mariano Fernandez Enguita. En: Didáctica Magna. Edición original de 1632. Madrid: Akal.

3. Comenio, J. A. (ob. Cit.) Pág. 71, 75.

4. Fenstermacher, G. (1989). Tres aspectos de la filosofía de la investigación sobre la enseñanza. En: La investigación de la Enseñanza I. Barcelona: Paidós.

5. Fenstermacher, G. (ob. Cit.) Pág. 154.

6. Fenstermacher, G. (ob. Cit.) Pág. 155.

7. Bruner, J. (1988) Realidad mental y mundos posibles. Barcelona: Gedisa. Pág. 83. 
8. Fenstermacher, G. (ob. Cit.) Pág. 158.

9. Fenstermacher, G. y Soltis, J. (1999). Enfoques de la Enseñanza. Buenos Aires: Amorrortu.

Pág. 23 y siguientes.

10. Fenstermacher, G. y Soltis, J. (ob. Cit.) Pág. 24.

11. Litwin, E. (2008). El oficio de enseñar. Condiciones y contextos. Buenos Aires: Paidós.

12. Litwin, E. (ob. Cit.) Pág. 26 y 27.

13. Litwin, E. (ob. Cit.) Pág. 26.

14. Litwin, E. (ob. Cit.) Pág. 15.

15. Dewey, J. (2000). Experiencia y educación. La educación tradicional frente a la educación progresiva. Edición original de 1938. Buenos Aires: Losada. Pág. 38.

16. Litwin, E. (ob. Cit.) Pág. 12.

17. Jackson, P. (2002). Práctica de la enseñanza. Buenos Aires: Amorrortu.

18. Jackson, P. (ob. Cit.) Pág. 159.

19. Jackson, P. (ob. Cit.) Pág. 165.

20. Fenstermacher, G. (ob. Cit.) Pág. 174.

21. Bain, K. (2007). Lo que hacen los mejores profesores universitarios. Valencia: PUV. Pág.

26 a 28.

22. Bain, K. (ob. Cit.) Pág. 14 y 15.

23. Bain, K. (ob. Cit.) Pág. 20.

24. Litwin, E. (ob. Cit.) Pág. 23 y siguientes.

25. Mercer, N. (1997). La construcción guiada del conocimiento. El habla de profesores y alumnos. Barcelona: Paidós.

26. Necuzzi, C. (2013). Desarrollo cognitivo involucrado en los procesos de aprendizaje y enseñanza con integración de las TIC. UNICEF, 2013.

http://www.unicef.org/argentina/spanish/Estado_arte_desarrollo_cognitivo.pdf

27. Camilloni, A. (2015) La formación básica en el currículum universitario. Conferencia 
en: Programa Universidad de Buenos Aires para el Siglo XXI. 21/09/15.

28. Serres, M. (2013) Pulgarcita. Buenos Aires: Fondo de Cultura Económica.

29. Merton, Robert K. (1980). Sobre las teorías sociológicas de alcance intermedio. En:

Teoría y estructura sociales. México: Fondo de Cultura Económica.

30. Perkins, D. (1995). La escuela inteligente. Del adiestramiento de la memoria a la educación de la mente. Barcelona: Gedisa.

31. Bruner, J. (1963). El proceso de la educación. México: UTEHA.

32. Martí, E. (2012). Desarrollo del pensamiento e instrumentos culturales. En: Desarrollo

cognitivo y educación (II). Carretero y Castorina. Buenos Aires: Paidós.

33. Perkins, D. (ob. Cit.) Pág. 81 y siguientes.

34. Litwin, E. (ob. Cit.) Pág. 89 y siguientes.

35. Bain, K. (ob. Cit.) Pág. 81 y siguientes.

36. Gardner, H. y Davis, K. (2014). La generación APP. Cómo los jóvenes gestionan su identidad, su privacidad y su imaginación en el mundo digital. Buenos Aires: Paidós.

37. Necuzzi, C. (2014). Enseñanza y construcción metodológica. El sentido ético de la educación y la condición humana en las propuestas de Edith Litwin. En: Homenaje a Edith Litwin. Lipsman, Mansur, Roig, Lion y Maggio coordinadoras-. Buenos Aires: Eudeba.

Bibliografía

Bain, K. (2007). Lo que hacen los mejores profesores universitarios. Valencia: PUV.

Bruner, J. (1988). Realidad mental y mundos posibles. Barcelona: Gedisa.

Bruner, J. (1963). El proceso de la educación. México: UTEHA.

Camilloni, A. y otras (2016). El saber didáctico. Buenos Aires: Paidós.

Camilloni, A. (2015). La formación básica en el currículum universitario. Conferencia en:

Programa Universidad de Buenos Aires para el Siglo XXI. 21/09/15.

Comenio, J. A. (1986). Introducción, por Mariano Fernandez Enguita. En: Didáctica Magna. Edición original de 1632. Madrid: Akal. 
Dewey, J. (2000). Experiencia y educación. La educación tradicional frente a la educación progresiva. Edición original de 1938. Buenos Aires: Losada.

Fenstermacher, G. y Soltis, J. (1999). Enfoques de la Enseñanza. Buenos Aires: Amorrortu.

Fenstermacher, G. (1989). Tres aspectos de la filosofía de la investigación sobre la enseñanza. En: La investigación de la Enseñanza I. Barcelona: Paidós.

Gardner, H. y Davis, K. (2014). La generación APP. Cómo los jóvenes gestionan su identidad, su privacidad y su imaginación en el mundo digital. Buenos Aires: Paidós.

Jackson, P. (2002). Práctica de la enseñanza. Buenos Aires: Amorrortu.

Litwin, E. (2008). El oficio de enseñar. Condiciones y contextos. Buenos Aires: Paidós.

Martí, E. (2012). Desarrollo del pensamiento e instrumentos culturales. En: Desarrollo cognitivo y educación (II). Carretero y Castorina. Buenos Aires: Paidós.

Mercer, N. (1997). La construcción guiada del conocimiento. El habla de profesores y alumnos.Barcelona: Paidós.

Merton, R. K. (1980). Sobre las teorías sociológicas de alcance intermedio. En: Teoría y estructura sociales. México: Fondo de Cultura Económica.

Necuzzi, C. (2014). Enseñanza y construcción metodológica. El sentido ético de la educación y la condición humana en las propuestas de Edith Litwin. En: Homenaje a Edith Litwin. Lipsman, Mansur, Roig, Lion y Maggio coordinadoras-. Buenos Aires: Eudeba.

Necuzzi, C. (2013). Desarrollo cognitivo involucrado en los procesos de aprendizaje y enseñanza con integración de las TIC. UNICEF. Disponible en: http://www.unicef.org/argentina/spanish/Estado_arte_desarrollo_cognitivo.pdf

Perkins, D. (1995). La escuela inteligente. Del adiestramiento de la memoria a la educación de la mente. Barcelona: Gedisa.

Serres, M. (2013). Pulgarcita. Buenos Aires: Fondo de Cultura Económica.

Abstract:

The forms of conservation of knowledge are diverse and have varied over time. We can recognize the staple (oral) societies where conservation is through oral stories learned and retained from memory, alphabetic societies (pre and post Gutenberg) with the primacy of the book and, finally, audiovisual societies (in the current Age of Information) where the written text is complemented with images and sounds. The various paths of knowledge support and distribution technologies and practices associated with them are extremely interesting (eg, the history of reading and writing) but will not be the subject of this work. Here we will focus on the transmission activity of the knowledge that occurs between the different subjects, subjects that in this relationship occupy 
different places both in relation to the initial possession or not of the knowledge as in the possibilities of its use and later reuse. This generic activity of transmission will be called teaching. And we will call didactics to the theoretical body that studies the practices of teaching, seeking to describe, explain and substantiate them, while also enunciating the norms for the best resolution of the problems that arise in the course of the activity itself.

Key words: education - teaching practices - didactics - knowledge - comprehension - language - university

Resumo: As formas de conservação dos saberes são diversas e mudaram ao longo do tempo. Podem-se reconhecer as sociedades ágrafas (orais) onde a conservação é através de relatos orais apreendidos e retenidos de memória, as sociedades alfabéticas (pre e pôs Gutenberg) com a primazia do livro e, finalmente, as sociedades audiovisuais (na atual era da informação) onde o texto escrito se complementa com imagens e sonidos. Os diversos percursos das tecnologias de suporte e distribuição do conhecimento e as práticas associadas a elas são muito interessantes (por exemplo, a história da leitura e da escritura), mas não é objeto deste trabalho. O centro será a atividade de transmissão dos saberes que se desenvolve entre os distintos sujeitos, que nesta relação ocupam lugares diferentes tanto em relação como a possessão inicial ou não dos saberes como nas possibilidades de seu uso e reuso posterior. A esta atividade genérica de transmissão se denominará ensino. E se denominará didática ao corpo teórico que estuda as práticas do ensino, procurando descrevê-las, explicá-las e fundamenta-las, às vezes que enunciar as normas para a melhor resolução dos problemas que se apresentam no transcurso da mesma atividade

Palavras chave: educação - práticas do ensino - didática - conhecimento - compreensão - linguagem universidade.

Educación, enseñanza y didáctica en la contemporaneidad fue publicado de la página 19 a página37 en Cuadernos del Centro de Estudios de Diseño y Comunicación № 67 